\title{
WRIST REHABILITATION WITH MANIPULATOR TO PERFORM PASSIVE AND ACTIVE EXERCISES
}

\author{
Piotr Kuryło ${ }^{1}$, Joanna Cyganiuk ${ }^{1}$, Peter Frankovský², Marianna Trebuňová ${ }^{3}$
}

\author{
${ }^{1}$ Institute of Machine Design and Operation, Faculty of Mechanical Engineering, \\ University of Zielona Gora, Poland \\ ${ }^{2}$ Department of Applied Mechanics and Mechanical Engineering, Faculty of Mechanical \\ Engineering, Technical University of Košice, Slovakia \\ ${ }^{3}$ Department of Biomedical Engineering and Measurement, Faculty of Mechanical Engineering, \\ Technical University of Košice, Slovakia
}

\begin{abstract}
The paper characterizes basic dysfunctions and diseases of a human wrist as well as describes the mechanics and pathomorphology of the human hand. The radial-carpal joint was analyzed in terms of its ranges of motion. The results of the analysis, i.e. the number of degrees of freedom for a free hand, are included. The concept of manipulator construction for optimal rehabilitation of the wrist was developed. Expected effects of the exercises, which can be implemented on the designed manipulator, were also described. A comparative analysis of other appliances supporting the rehabilitation of the human upper limb were presented. The main purpose of the designed manipulator was to gain full control of implementation of exercises performed by the patient and to archive and precisely track the progress in the rehabilitation. An important feature of the designed manipulator is its versatility enabling its use for: exercises of both hands (left and right) with the repetitive movements, choose of exercises (active and passive movements), choose of the degree of disability of the patient.
\end{abstract}

Keywords

rehabilitation manipulator, wrist, rehabilitation

\section{Introduction}

Restoration of the physical performance of a human's joint is conditioned by an effective rehabilitation process. Human disabilities may result from illnesses, accidents or the aging process. Effective rehabilitation depends mainly on the regularity and the number of exercises performed. Therefore, rehabilitation manipulators are used more and more often in the rehabilitation of limbs.

The development of technology, the modernization of industry, agriculture and motorization causes that the number of serious limb injuries increases every year. Their consequences are paresis, paralysis affecting mobility restrictions not only in the post-traumatic phase, but also in the subsequent life. Joints which are exploited and burdened throughout the whole human life are susceptible to degenerative changes. Exercises have a beneficial effect on the entire human body and in particular on the full range of joint mobility. Medical rehabilitation of the upper limb, the wrist in particular, is often a process requiring the intense work of both the physiotherapist and the patient. It is not only tiring and very expensive but also requires specialist knowledge. It is worth, even in a minimal scale, replacing physiotherapists with manipulators to support movements performed by patients being rehabilitated. Thus, demand for this type of manipulators is considerable.

We are currently observing the continuous development of medical rehabilitation, where not only physicians take part, but also interdisciplinary teams composed of scientists associated with such fields of knowledge as biomechanics, material engineering, construction and design, electronics, informatics. The conducted research allows for a better understanding of the functioning of the human body, which is associated with the development of more and more effective methods of treatment and rehabilitation of people with an arbitrary dysfunction of the musculoskeletal system. The development and progress made in its rehabilitation are very visible. 


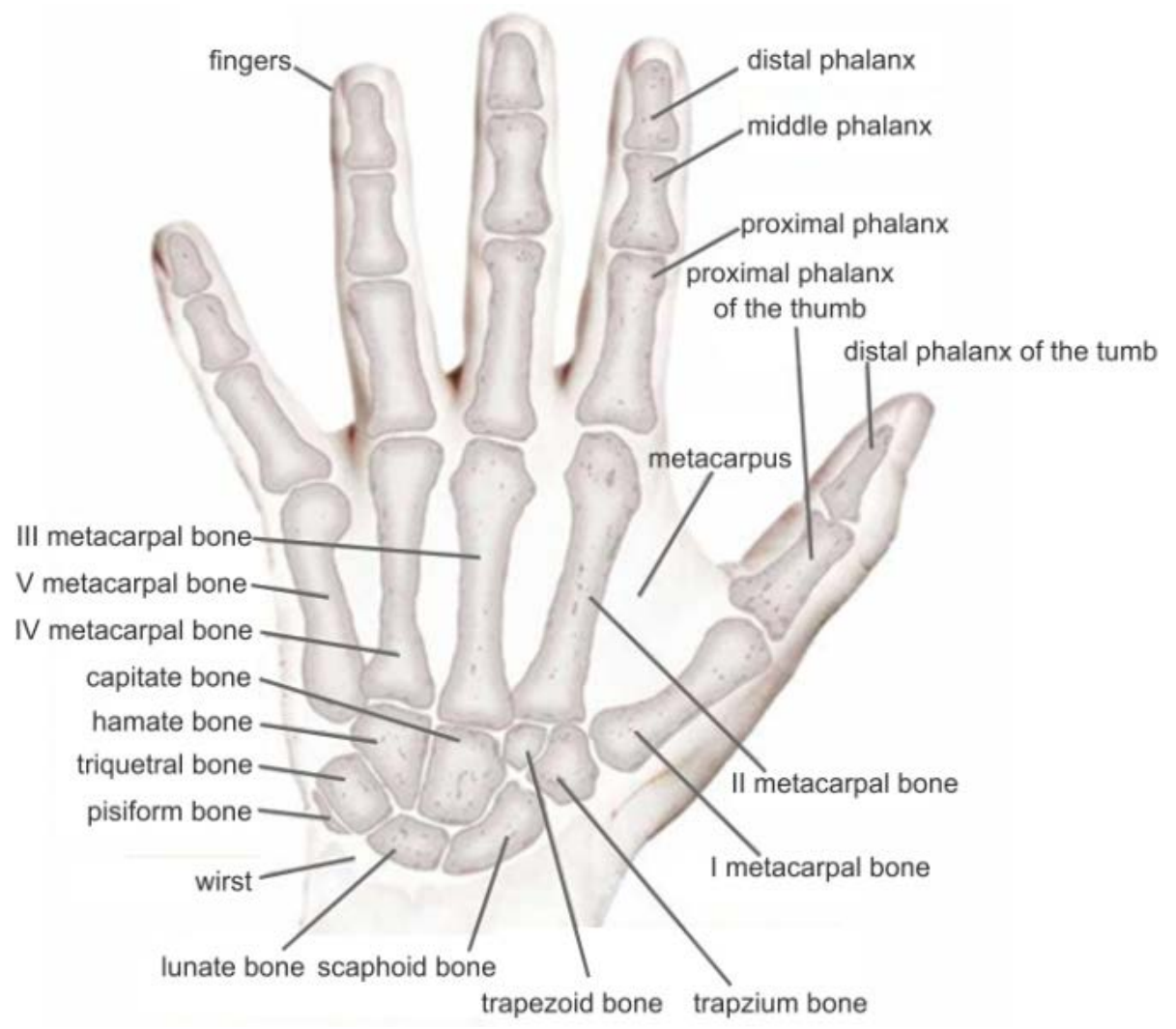

Fig. 1: The bones of the hand. Created using [3], with permission.

The paper proposes the concept of a manipulator for wrist rehabilitation, allowing the implementation of passive and active (with and without resistance) exercises. The main purpose of the proposed manipulator is to control the movement of the wrist while performing rehabilitation exercises. Thanks to the control and archiving of individual movements of the wrist during exercise, it is possible to quickly analyze the progress.

Many of the research works concern the use of computer technologies to create dedicated exercise programs, allowing to determine kinematic parameters, the shape of the trajectory of movement, and interaction algorithms between the patient and the machine, in order to perform exercises in a passive or active mode.

A very important issue in rehabilitation robots is a proper safety system. The manipulator could not hurt either the patient or people around him. The manipulator must be equipped primarily with electronic, mechanical and electrotechnical protections, but also with software protection.

\section{Mechanics and pathomechanics of hand}

The radial-carpal joint operates with the help of appropriate muscles. These include the muscles connecting the radius bone with the distal and proximal rows of the wrist bones. In addition, $3 / 4$ of the wrist surface is the radial bone, and $1 / 4$ is the joint's disk.

The mid-carpal joint allows the connection of both rows of the wrist bone [1]. The most important joint surfaces that appear here are the head and the articular fossa, which builds the joint surfaces. They are adjacent to the individual carpal bones (Fig. 1) [2].

Various types of ligaments are described below:

- palmar ulnocarpal ligament-from the proximal row of carpal bones to the radial styloid process,

- palmar intercarpal ligaments-between the capitate bone and the surrounding bones,

- interosseous intercarpal ligaments-joins all the articular surfaces of bones of the distal row,

- dorsal intercarpal ligaments-run transversely or obliquely from one bone to another [4].

Mobility is a concept that defines the range of movements occurring in the joints. This is one of the basic functionalities of joints. The range of movements is often called flexibility, and the level of this mobility depends on the passive structures of connections in the form of joint surfaces, joint capsules and ligaments or from active structures, and thus from muscles. Due to the fact that they surround joints, they are responsible for their operation, and also are often responsible for any emerging movement restrictions [5]. 
Skeletal mobility can be divided into:

- active - the range of motion that is obtained by activating moments of muscle strength within a given joint,

- passive-range of motion obtained thanks to the moment of external forces; the muscles behave passively [5].

The carpus performs movements such as: flexion and straightening, as well as abduction and adduction [6].

Ligaments that work within the hand are primarily:

- dorsal radio-carpal ligament-stretches from the edge of the dorsal joint surface of the carpus of the radius bone to the dorsal surface of the bone of the proximal row of the system,

- radiocarpal palmar ligament-stretches from the radial styloid process to the proximal row of a given capitate bone,

- ulnar collateral ligament of the carpus-stretches from the ulnar styloid process around the heads of the capitate and lunate bones,

- radial collateral ligament of the carpus-joins the radial styloid process and the scaphoid bone,

- ligamentum arcuatum carpi palmare-from the ulnar styloid process around the heads of the capitate and lunate bones,

- ligamentum arcuatum carpi dorsale-stretches from the scaphoid bone to the triquetral bone [7].

\section{The range of motions in the radio- carpal and radial-ulnar joints}

A medical goniometer is used to check the range of motion in the joints. It helps in checking whether there is contracture, insufficiency in a given joint and it is helpful in determining progress during rehabilitation [5].

The measured range of motion in these joints includes

- extension,

- flexion,

- radial flexion,

- supination,

- pronation,

- ulnar flexion.

According to several studies, there are methods of measuring motion in the radio-carpal joint [8-10].

\section{Hand and its degree of freedom}

The number of degrees of freedom of a rigid body is the number of all independent coordinates that uniquely define its position in space in a particular reference system. Most often, a free member that is suspended in a given space is characterized by 6 degrees of freedom of movement. The most important of them should be primarily [5]:

- 3 translation movements along the $\mathrm{x}, \mathrm{y}, \mathrm{z}$ axis,

- 3 rotational movements around the same axis.
The human hand can be anatomically divided into 18 parts. Each of them is connected with 17 moving elements. Each of them also has 22 degrees of freedom and 23 degrees of mobility [11].

\section{The concept of the rehabilitation manipulator}

Physical exercises represent the main treatment in the rehabilitation of patients with injured wrists. Wrist rehabilitation is usually a process that requires a patient and a physiotherapist to work hard. Robots and rehabilitation manipulators relieve the physiotherapist. The proposed device, helpful in wrist rehabilitation, enables precise repetition of movements, and adjusting the speed and strength of action. Exercises of the wrist strengthen muscle and bone endurance, and improve the efficiency of the entire hand. Whereas the lack of exercise (due to long-term immobilization or resulting from an illness) negatively affects the functioning of the joints. The effectiveness of rehabilitation of disabled people can be increased through the use of robots or rehabilitation manipulators. Rehabilitation robots are used by physiotherapists as a complementary solution. The scope of operation of such a robot should be similar to the movements of the rehabilitated joint, in this case the wrist.

\section{Engineering design}

In the treatment of patients with various disabilities of the motor organs, devices which support the rehabilitation process are used increasingly frequently. The paper proposes the concept of a mechatronic system to support wrist rehabilitation. The manipulator is planned to allow the height adjustment, to use force sensors, stepper motors, controllers, etc. Its main task will be to use the technique of active exercises with strength control.

In the design and implementation of mechatronic systems supporting motor rehabilitation, it is necessary to use modern computer tools that enable modeling, simulation, verification and optimization of the resulting solutions. The basic condition is, however, extended knowledge due to the interdisciplinary nature of the issue, which includes engineering disciplines, such as mechatronics and IT and medical, such as rehabilitation and neurophysiology. An essential and inseparable stage of implementation and verification of the developed devices are clinical trial examinations. The use of information technology opens new perspectives for increasing the effectiveness of rehabilitation by introducing a motivating factor, which is the possibility of active cooperation of the patient with the mechatronic system [12]. In the process of development of methods using mechatronic technologies to support motor rehabilitation, the following issues are of fundamental importance [13]: 
- algorithms of exercise programs including patientmachine interactions,

- flexibility and the ability to adapt the system to the patient's needs,

- application of new technologies,

- the user safety,

- test procedures and certifications.
(3). The impact on the wrist around the working axes is measured using a force sensor (8). As mentioned earlier, the manipulator allows you to perform passive and active exercises of the wrist.

During active exercises, the disabled persons perform specific limb movements by themselves. Basic data such as: resistance of the mechanism, movement and speed

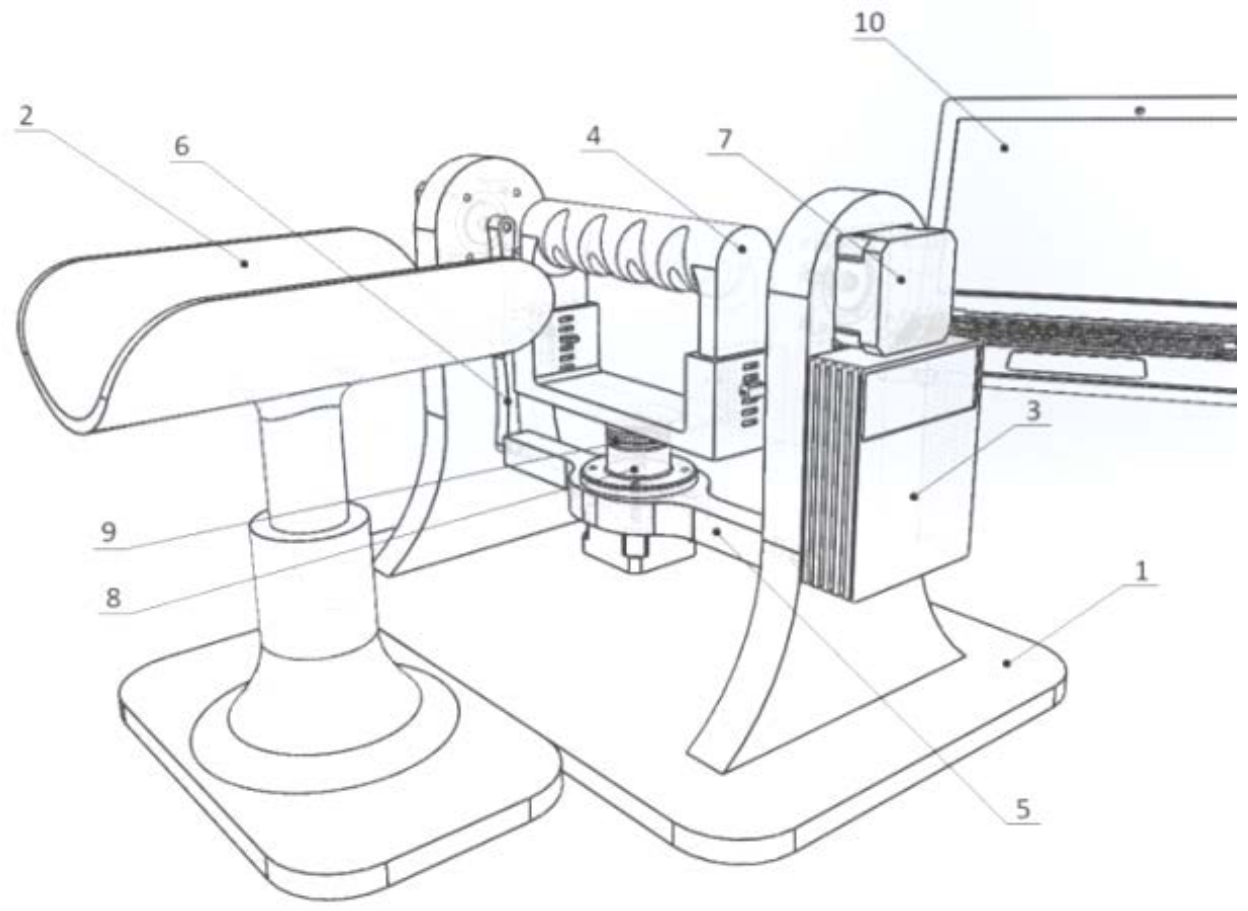

Fig. 2: Manipulator for wrist rehabilitation: 1-base, 2-adjustable support for the forearm, 3-stepper motor controller, 4-adjustable handle, 5-swivel arm, 6-main arm, 7-stepper motor, 8-force sensor, 9-swivel head, 10-computer.

Fig. 2 presents a concept of a set for wrist rehabilitation. The set consists of a base (1) with two columns that support the entire structure of the device. Between the columns there is an arm with a suspended adjustable handle (4). This solution allows adjusting the height of the hand to the main axis of the "cradle" (5). The main arm (6), with one degree of freedom, performs a rotary movement; this movement is consistent with the movement of the wrist (flexing and straightening). The second degree of freedom is a rotating manipulator grip. The handle makes a swing motion around its own axis. This degree of freedom is used during rotary exercises of the forearm as well as the adduction and abduction, depending on the setting of the main arm. The patient's forearm rests on a comfortable support (2), which is also adjustable.

The proposed manipulator uses a stepper motor drive (e.g. 39BYGH402B) (7), which ensures precise rotation in particular directions and is controlled by a controller can be programmed with the use of a computer (10). Whereas in the passive exercises, wrist movement is forced by the manipulator and supervised by a physiotherapist using a computer. Thanks to the suitable software, it is possible to record the movements of the wrist during the exercises. The recording is very helpful not only for the physiotherapist, but also for to motivate the patients. Thanks to the active exercises and data archiving, it is possible to monitor and control the rehabilitation progress.

An important feature of this manipulator is its versatility, since it can be used in both left and right hand exercises. The manipulator setting should include:

- repeatability of movements,

- selection of exercises (active, passive),

- the degree of disability of the patient,

- force regulation,

- the angle of the wrist operation,

- selection of the limb (right, left). 


\section{The range of exercises possible to be performed on the rehabilitation manipulator}

\section{Abduction and adduction in the carpal joint}

Fig. 3 presents the most common ranges of exercises that can be performed on a designed manipulator.

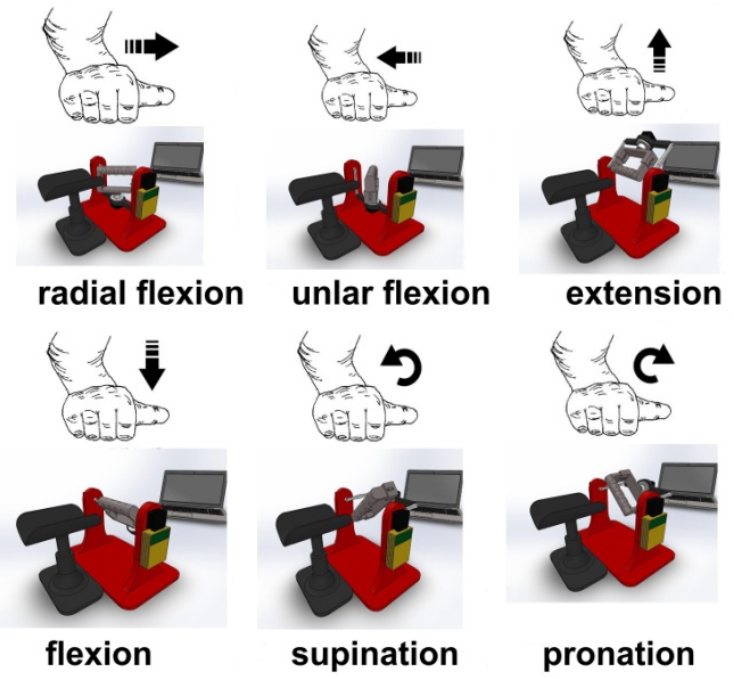

Fig. 3: Range of exercises possible on the manipulator.

In the radial flexion, movements are performed in the frontal plane. The hand (palm side) rests on the manipulator handle. The base of the second metacarpal bone is the axis of rotation.

In the ulnar flexion, movements are also performed in the frontal plane. The hand (palm side) is based on the manipulator handle. The base of the second metacarpal bone is the axis of rotation.

In exercising the extension, the movement is performed in the sagittal plane. The forearm is flexed in the elbow joint, in pronation, at the angle of $90^{\circ}$. During the exercise, the palm rests on the handle.

In exercising the flexion, similarly to the extension, the movement is performed in the sagittal plane. The forearm is flexed in the elbow joint, in supination, at the angle of $90^{\circ}$. During the exercise, the palm rests on the handle.

In exercising the forearm supination, the movement is performed in the transverse plane. The elbow joint rests on the support and flexed at the angle of $90^{\circ}$. The forearm is in the intermediate position between supination and pronation, the clamped fist holds the handle.

In exercising the pronation of the forearm, the movement is also performed in the transverse plane. The elbow joint rests on the support and is flexed at an angle of $90^{\circ}$. The forearm is in the intermediate position between supination and pronation, the clamped fist holds the handle.

\section{Exercises that can be practiced on the rehabilitation manipulator}

An important factor, in the correctness of performing wrist exercises, is the compatibility between the wrist axis and the axis of rotation of the manipulator, which allows repeated and precise movements (with adjustable speed) of the patient's wrist. The described manipulator should, to a considerable extent, relieve the physiotherapist and is intended for people who have lost their wrist mobility as a result of illness or injury. In the initial period of rehabilitation, passive exercises frequently dominate. The manipulator aims to maintain a certain range of motion, thus eliminating paresis or contractures. For this reason, performing passive rehabilitation, the wrist performs programmed movements. The patient's task is to try to counteract particular movements of the manipulator. Strength, speed and angle of rotation can be set individually for each patient separately. Whereas in active rehabilitation, patients perform movements on their own. In this case, the resistance can be adjusted in a performed exercise.

The manipulator has two degrees of freedom. This solution enables performing the following movements:

- extension and flexion,

- radial abduction and ulnar adduction,

- supination and pronation.

\section{Results of exercises interpreted on the rehabilitation manipulator}

The presented model of the manipulator enables performing exercises of the upper limb in the wrist area. At the conceptual stage of the mechatronic system supporting rehabilitation, the following operation options are provided:

- passive rehabilitation-manipulator provides exercises of movement of a selected trajectory,

- active rehabilitation-patients perform the movements on their own, depending on the disability,

- active rehabilitation with resistance-strengthening muscle strength.

Passive exercises aim at:

- maintaining the appropriate level and range of movement performed in the joints,

- maintaining the correct length, flexibility and elasticity level of all muscles,

- prevention of contractures of muscle, articular capsules and ligaments,

- stimulation of the peripheral nervous system.

The most important active exercises (i.e. where patients perform the exercises themselves) include:

- increase in muscle strength,

- increase in muscle mass,

- restoring the proper level of muscle function. 
The general benefits that the use of rehabilitation robots can bring when exercising the wrist are primarily:

- increasing the level of precision of movements performed during exercises, their repeatability and the ability to program the entire sequence of more complex movements,

- providing conformity between of the direction and the degree of implemented changes in the movement parameters, which conditions the results achieved during training sessions,

- increasing the effectiveness of the therapy used,

- shortening (significantly) the duration of the whole therapy.

It is worth noticing that the use of individual robots is never the only rehabilitation method applied for a patient. It is only a kind of supplementation for other activities, pharmacology including.

\section{Conclusion}

Modern technology increasingly meets the needs and expectations of modern medicine. Thanks to the progress and creation of subsequent solutions, it is possible to automate practically every stage of treatment. It turns out that thanks to this facilities, the process is not only much more effective and brings the expected results faster, but also seems to be less invasive for the patients. Thanks to this, it is easier for them to return to full or significant efficiency and fitness, and the process itself is much shorter.

The use of rehabilitation devices in improving the efficiency of the wrist is today one of the basic methods of formation of the whole program of restoring patients' physical fitness. They are used to conduct treatments (cryotherapy, laser therapy, etc.) or to perform specific exercises. Machine aided treatment is much more effective due to the fact that machines provide ability to adapt to the current needs and expectations of the patient, doctor and physiotherapist. Thanks to the use of various devices in physiotherapy, including the manipulator, physiotherapists may put less and less physical effort into exercising with the patient. This role is taken over by the device. The task of the physiotherapist is to ensure the proper work of each side, to program subsequent exercises, to set the device properly to match it to the capabilities and needs of a given patient.

The method of operation and the construction of the manipulator intended for the rehabilitation of the wrist definitely increases the efficiency, purposefulness and, above all, the quality of the exercises. Its use can bring many more benefits for the patients, who may have the opportunity to quickly return to full (or significant) physical fitness. Thanks to the developed manipulator, exercises are performed more accurately, and the device forces the patient to be more involved in the rehabilitation process, to perform the assigned exercises correctly and exactly and to master the technique of their execution.

The rate of the technological progress allows us to suppose that both in medicine and in rehabilitation, devices that facilitate treatment will be increasingly used. They will also be constantly improved, so it may be assumed that their efficiency will be increasingly greater.

\section{Acknowledgement}

This work has been supported by the state grants KEGA 069TUKE-4/2017 (25\%), VEGA 1/0290/18 (25\%) of the Ministry of Education of the Slovak Republic and APVV-15-0356 (25\%), APVV-17-0258 (25\%).

\section{References}

[1] http://chirurgiareki.pl/userfiles/pdf/27Pl.pdf [Internet]. [cited 2018 Jan 12]

[2] Tejszerska D. Biomechanika narządu ruchu człowieka. Wyd. ITEW, Gliwice - Radom. 2011;247-253.

[3] Trawiński K. Kosci reki [Internet]. [cited 2018 Jan 11]. https://www.medianauka.pl/kosci-reki.

[4] http://anatomia.wyklady.org/wyklad/966_stawy-i-ruchyobreczy-konczyny-gornej_strona-4.html [Internet]. [cited 2018 Jan 2].

[5] http://www.fizjoterapeutom.pl/files/13/rehabilitacja_reki.pdf [Internet]. [cited 2018 Jan 3].

[6] Sobieszczyk S. Modelowanie biomechaniczne, Wyd. PG, Gdańsk. 2006;7-12.

[7] Gilroy AM. Atlas anatomi. Wyd. MedPh, Warszawa. 2011;300-7.

[8] Živčák J, Knežo D. Biomechanika hybnosti. 1st ed. Prešov: Prešovská univerzita; 2007. 205 p. ISBN 978-80-8068-675-8.

[9] Kilar JZ. Leczenie ruchem. Kraków 1996, Wydawnictwo Firma Handlowo- Usługowa KASPER. pp. 67-73.

[10] Živčák J, Michalíková M, Tóth T, Bednarčíková L. Goniometria pohybovej sústavy človeka, 1. ed. Košice: TU; 2012. 297 p. ISBN 978-80-553-0532-5.

[11] Matejko B. Idea protez bionicznych w nowoczesnej protetyce. Zeszyty Naukowe. 2010;1:185-9.

[12] Giesko T. Model mechatronicznego systemu do wspomagania rehabilitacji ruchowej. Problemy Eksploatacji. 2012;2:68-71.

[13] Mikołajewska E. Wykorzystanie robotów rehabilitacyjnych do usprawniania. Niepełnosprawność-zagadnienia, problemy, rozwiązania. 2013;9(4):21-44.

Piotr Kuryło, Ph.D.,Hab, Eng. Prof. UZ Faculty of Mechanical Engineering Institute of Machine Design and Operation University of Zielona Gora Szafrana 4 st., 65-516 Zielona Gora E-mail: p.kurylo@ibem.uz.zgora.pl Phone: +48 683282577 